\title{
Measuring the economy in the age of digitalisation
}

Written by: Nadim Ahmad, OECD Statistical Directorate and Neïla Bachene, OECD Observer

Last update: 9 March 2017

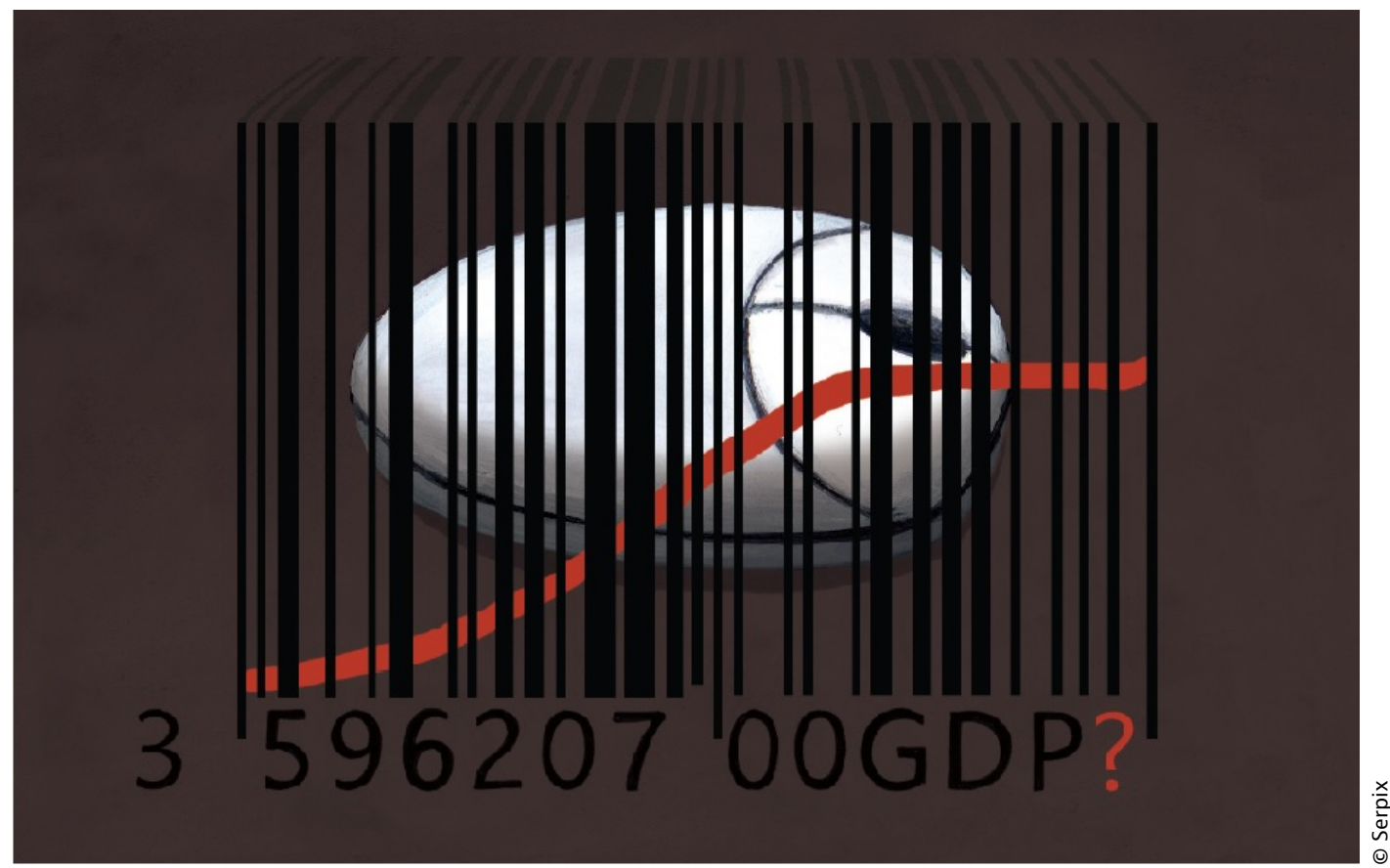

Recent years have seen a rapid rise in digital transactions, notably through web-based "sharing economy" platforms that have bridged, and indeed blurred, the gap between consumers and producers. But this upsurge has also created new challenges for measuring GDP, and, against a backdrop of slowing rates of productivity growth, has led some to question whether the slowdown reflects these new transactions.

The underlying activities related to consumer-to-consumer transactions, which characterise the so-called "sharing economy", are not that new. Households have long engaged in renting out their homes, offering taxi services and selling secondhand goods via the small ads in newspapers. Conceptually, GDP captures these activities and in practice countries have used a variety of approaches to measure them.

However, these activities have generally been small scale in nature, and so the approaches used to measure them have tended to elude scrutiny. What is "new" is 
the much larger scale of such transactions: Airbnb, for example, which specialises in consumer-to-consumer holiday rentals, now has a market capitalisation close to that of Hilton Hotels group. The question is not whether the accounting framework for GDP includes these transactions, but whether the current metrics, which were intended to measure low-scale and insignificant sums, are robust enough to adequately measure the same, albeit larger, activities today.

On balance, for consumer-to-consumer transactions, the available evidence suggests this is largely the case; indeed, the underlying activities resemble transactions in the informal, grey or shadow economy where a significant body of measurement guidance has been built up and implemented over the years. However, things are less clear concerning the margins paid to the intermediaries running these platforms, which are also part of GDP, and especially when the payments for the related intermediation services cross borders. True, some useful data can be retrieved, for instance, from tax data as those selling services using platforms such as Airbnb are likely to declare income to the tax authorities, especially in countries where VAT is applied. But what about the wider macroeconomic aspects?

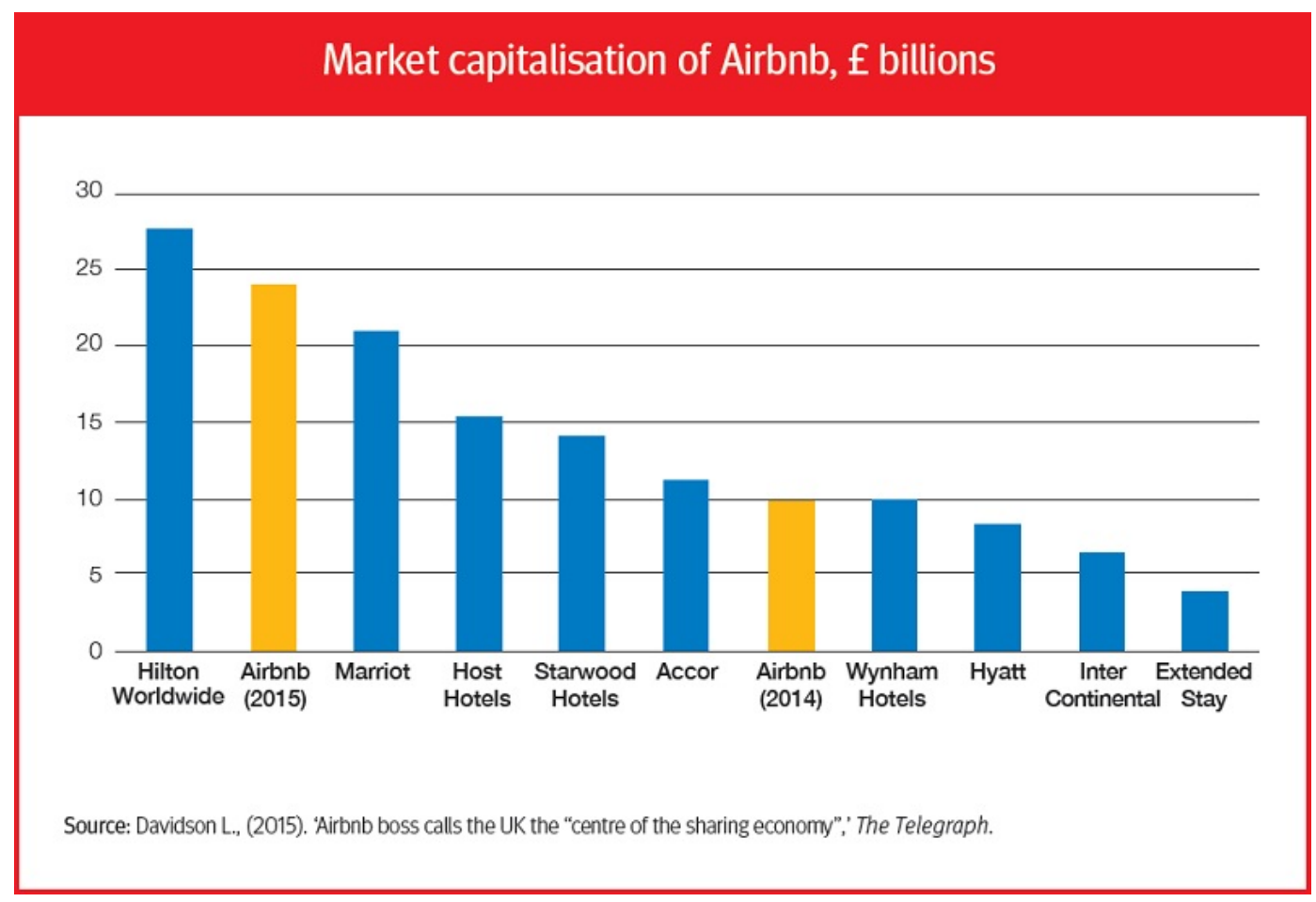

Perhaps one of the main criticisms of GDP concerns its conceptual scope and in particular how it treats transactions of goods and services that are effectively provided for free. Digitalisation has given consumers access to a multitude of maps, search engines, news, videos, social networking, cloud storage, and applications, all without any need to pay a fee. Indeed, it has also generated free benefits for producers, for example, through operating systems such as Linux. Because these are free, there is no explicit corresponding consumption recorded 
in GDP, nor are there estimates of household consumption or expenditures, including capital, by businesses. This has led some to question whether the scope of GDP is overly restrictive, particularly as the provision of free goods and services appears to widen the gap between GDP and measures of material well-being and consumer surplus. These criticisms in part reflect a misunderstanding of what GDP is (a measure of the income generated from production) and what it is not (a measure of well-being). But they also reflect a misunderstanding of the business models used to finance the provision of free goods and services. Many, if not most, of these models are financed via advertising or the acquisition of Big Data-the wealth of information generated by online users about their habits, preferences and so on that marketers attach such value to. The ad model is not new: after all, free television programmes and newspapers financed via advertising pre-date the digital revolution. In any case, at least some consumers eventually pay by buying the advertised products, which are not really free at all.

The provision of free services financed via Big Data raises thornier (but again not new) issues for the conceptual accounting framework, particularly with regards to the implications on the measurement of knowledge, and by extension human capital, and whether these should be included within the GDP production boundary; discussions among national accountants continue.

\section{Consumers as producers}

The digital revolution has also blurred other traditional borderlines, such as the use of household-based web search engines to book flights, previously the preserve of travel agents. Has this shift to the individual (participative production) meant a corresponding hole in GDP? By convention, the answer is no, and certainly no more than doing your own cooking or shopping, largely reflecting the fact that the inclusion of households' own production of services for their own consumption would potentially render GDP meaningless for macro-economic policy making, as the size of these non-market activities would swamp market based activity. However, that it is not to say that these flows are ignored by statisticians, on the contrary: the OECD, among others, has been estimating the size of these activities to complement GDP measures.

What about web knowledge based assets produced by households such as Wikipedia and Linux? These public goods are financed by voluntary donations (of time and money) from members of the public. Although time spent on these activities, for instance, updating a Wikipedia page, may include an element of production, the services provided in building up these public goods do not by and large show up in GDP; and because production is effectively free, as is the user of the assets, so too is the value of the assets. This partly reflects the fact that ownership of the assets is collective and so cannot be allocated to any particular economy. However, that is not to say that they are worthless, or that they have no 
value to users or the economy, and work is under way to estimate those economic benefits.

\section{Digitalisation and prices}

All of the above relates (largely) to the measurement of GDP in current prices, but there is also great interest in understanding the volume of GDP changes over time by adjusting for inflation. What is clear is that digitalisation affects prices. Airbnb is regarded as competitive, as are car sharing firms such as Blablacar. But is there a quality improvement in the services provided, compared to the conventional services they displace, that is not picked up in measures of inflation and price change? Has participative production in particular led to an increase or a decrease in the quality of the rented apartment or car trip, for example?

The Internet has had a democratising effect that has reduced the space between buyers and producers, in the process piloting consumers towards cheaper suppliers and producers of goods and services, even with the same country. This reduces, other things being equal, recorded

The Internet has had a democratising effect that has reduced the space between buyers and producers consumption for a given basket of products. But conventional price indices may not be able to capture this substitution effect, similar to the outlet bias problem (assuming of course that quality is unchanged) when people buy normal goods online or directly from wholesalers, and so possibly underestimating the effect on volume output. In short, digitalisation has exacerbated age-old problems in measuring price change and the grey area between price and quality. But progress has been made, for example, with the Eurostat-OECD Methodological Guide for Developing Producer Price Indices for Services (SPPI, 2014), which provides detailed guidance on price measurement across a range of services.

Overall, many criticisms of the conceptual accounting framework appear to confuse what GDP is and what it is not. However in many areas, notably prices, practical measurement of digital-related activities remains a challenge. Ironically, the new digital intermediaries may also hold the solution, because they provide potential access to data in what were previously unreported and invisible transactions. Work is on-going, including under the auspices of the G20 and the OECD Working Parties on National Accounts and Trade in Goods and Services, to address these issues and to assess the size of the potential impact digitalisation may have on metrics of economic growth.

For UK and Ireland examples of tax and letting, see www.gov.uk/rent-room-inyour-home/the-rent-a-room-scheme, and www.revenue.ie/en/tax/it/rentalincome.html 


\section{References}

Measuring GDP in a Digitalised Economy http://dx.doi.org/ 10.1787/5jlwqd81d09r-en

Lequiller, François (2004-2005), "Is GDP a satisfactory measure of growth?", OECD Observer No 246-247, December 2004-January 2005 http:// oecdobserver.org/news/archivestory.php/aid/1518/

Is_GDP_a_satisfactory_measure_of growth.html 